\title{
Direct Hydrogel Encapsulation of Pluripotent Stem Cells Enables Ontomimetic Differentiation and Growth of Engineered Human Heart Tissues
}

\author{
Authors: \\ Petra Kerscher ${ }^{1}$, Irene C Turnbull ${ }^{2}$, Alexander J Hodge ${ }^{1}$, Joonyul Kim ${ }^{3}$, Dror Seliktar ${ }^{4}$, \\ Christopher J Easley ${ }^{3}$, Kevin D Costa ${ }^{2}$, Elizabeth A Lipke ${ }^{1, *}$
}

\begin{abstract}
Affiliations:
${ }^{1}$ Department of Chemical Engineering, Auburn University, AL, USA.

${ }^{2}$ Cardiovascular Cell and Tissue Engineering Laboratory, Cardiovascular Research Center, Icahn School of Medicine at Mount Sinai, New York, NY, USA.

${ }^{3}$ Department of Chemistry and Biochemistry, Auburn University, AL, USA.

${ }^{4}$ Department of Biomedical Engineering, Technion-Israel Institute of Technology, Haifa, Israel.

*Correspondence to: elipke@auburn.edu
\end{abstract}




\begin{abstract}
Human engineered heart tissues have potential to revolutionize cardiac development research, drug-testing, and treatment of heart disease; however, implementation is limited by the need to use pre-differentiated cardiomyocytes (CMs). Here we show that by providing a 3D poly(ethylene glycol)-fibrinogen hydrogel microenvironment, we can directly differentiate human pluripotent stem cells (hPSCs) into contracting heart tissues. Our straight-forward, ontomimetic approach, imitating the process of development, requires only a single cell-handling step, provides reproducible results for a range of tested geometries and size scales, and overcomes inherent limitations in cell maintenance and maturation, while achieving high yields of CMs with developmentally appropriate temporal changes in gene expression. Here we demonstrate that hPSCs encapsulated within this biomimetic 3D hydrogel microenvironment develop into functional cardiac tissues composed of self-aligned CMs with evidence of ultrastructural maturation, mimicking heart development, and enabling investigation of disease mechanisms and screening of compounds on developing human heart tissue.
\end{abstract}

Keywords: Engineered cardiac tissue, PEG-fibrinogen, embryonic, pluripotent, stem cell, developing heart tissue, maturation, microenvironment, hydrogel 


\section{Introduction}

Limited access to samples of human cardiac tissue severely impedes cardiology research, drug discovery, and clinical cardiac regeneration efforts. Indeed, predicting cardiac toxicity and the triggering of arrhythmias represents a major hurdle for pharmaceutical compound development, resulting in $20-30 \%$ of drugs receiving a black box warning or being withdrawn from the market $^{1,2}$ and having devastating economic and societal consequences. Human pluripotent stem cells (hPSCs) provide the potential to produce large quantities of physiologically relevant, species-specific and even patient-specific cardiomyocytes (CMs) in vitro through directed differentiation. Engineered human heart tissues created from such cells can address the challenge of widespread cardiac tissue access, thereby providing the ability to study normal and abnormal human heart development, as well as revolutionizing high-throughput drug screening, modeling of human cardiac diseases, and the field of regenerative medicine. However, these tissues must develop structural and functional properties representative of the native human myocardium ${ }^{3}$, and their fabrication needs to be straightforward, automatable, scalable, and highly reproducible ${ }^{4}$. Achieving these goals has proven difficult.

Originally, hPSC differentiation protocols used cell aggregation to create 3D embryoid bodies $(\mathrm{EBs})^{5,6}$, which facilitated hPSC differentiation into spontaneously beating stem cellderived cardiomyocytes (SC-CMs). To overcome the issues of inefficient $\mathrm{CM}$ production and irregular reproducibility using this EB cardiac differentiation protocol, researchers have recently focused on modulating the chemical environment of differentiating SC monolayers. Through the temporal introduction of soluble factors, this approach strives to replicate the cues directing native heart development ${ }^{6,}$. These highly efficient 2D differentiation protocols have 
revolutionized $\mathrm{CM}$ production from $\mathrm{hPSCs}^{8,9}$; however, this monolayer-based approach does not replicate the fundamental 3D nature of myocardial development.

Tissue engineering offers a 3D solution to the 2D cell culture problem. The established paradigm for creation of engineered heart tissues requires a source of CMs, either isolated from rodent hearts or pre-differentiated from PSCs. Following dissociation, the CMs are combined with a biomaterial scaffold and re-assembled into cardiac tissues ${ }^{10-14}$. Although this approach has been successful in creating human cardiac tissue, the required pre-differentiation and subsequent dissociation of spontaneously contracting SC-CMs precludes direct production of mature cardiac tissues from hPSCs and hinders investigation of the role of cellular microenvironment during early human cardiac development. The multiple cell-handling steps involved create not only processing and fabrication challenges, and limit the ability for tissue biomanufacturing, but also disrupt important cell-cell junctions, and cause a high degree of cell loss. Establishing a simple workflow that reduces the number of cell-handling steps and provides a 3D microenvironment throughout differentiation would transform the fabrication of human cardiac tissues, which will be critical for their successful utilization in developmental biology research, high-throughput pharmaceutical screening, and generation of mature SC-CMs for basic science and clinical applications.

Natural biomaterials (e.g., fibrin, gelatin, Type-I collagen) have been used most frequently to support classic engineered cardiac tissue formation ${ }^{10,13,15}$ but present limitations due to their inherent batch-to-batch variability, lack of immediate structural support, and the degradation of contractility during long-term cardiac tissue maintenance in vitro. In comparison, synthetic materials are completely defined and rapidly crosslinkable with tunable properties, but typically lack biological components inherent to natural scaffolds. Hybrid biomaterials, having 
both natural and synthetic components, provide unique advantages for tissue engineering applications. Particularly relevant to forming cardiac tissues, hybrid biomaterials have tunable mechanical properties combined with natural sites to support cell survival, adhesion, proliferation, and differentiation, as well as degradation and remodeling of the scaffolds ${ }^{16,17}$. Therefore, employing hybrid biomaterials, such as poly(ethylene glycol)-fibrinogen (PEGfibrinogen), enables properties of both components to be exploited in guiding hPSC differentiation and the process of human engineered cardiac tissue formation (Table S1).

Here we asked whether it is possible to directly create a $3 \mathrm{D}$ tissue construct emulating key stages of cardiac embryologic development, growth, and maturation in an ontogenymimicking (i.e., ontomimetic) model of human heart muscle. We found that human induced pluripotent stem cells (hiPSCs) can successfully be differentiated into contracting CMs while encapsulated within PEG-fibrinogen hydrogels, thereby directly forming functional 3D developing human engineered cardiac tissues (3D-dhECTs) with a single cell-handling step during the cell-encapsulation process.

For the first time, we have successfully encapsulated and differentiated hiPSCs within a controlled biomimetic hydrogel microenvironment, achieving developmentally-appropriate temporal changes in gene expression, high $\mathrm{CM}$ yield, and calcium handling properties similar to age-matched CMs produced using high-efficiency 2D monolayer differentiation. Furthermore, CMs within our 3D-dhECTs became progressively anisotropic without external electromechanical stimuli and developed ultrastructural features characteristic of mature CMs. These results demonstrate that providing a 3D architecture during and after hiPSC differentiation without disturbing cell-cell junctions and providing continuous 3D cell-cell and cell-material interactions is advantageous for creating an ontomimetic model of native human myocardium. 


\section{Materials and methods \\ HiPSC expansion and culture}

IMR-90 Clone 1 and 19-9-11 human induced pluripotent stem cells (hiPSCs) were purchased from $\mathrm{WiCell}$ and maintained at $37^{\circ} \mathrm{C}, 5 \% \mathrm{CO}_{2}$, and $85 \%$ relative humidity. HiPSCs were cultured as colonies on hESC qualified Matrigel (BD Biosciences) using mTeSR-1 medium (Stem Cell Technologies). HiPSCs were passaged using Versene (Life Technologies) and $5 \mu \mathrm{M}$ ROCK inhibitor (Y-27632, R\&D Systems) was added to the mTeSR-1 medium for $24 \mathrm{~h}$ post-seeding.

\section{Glass acrylation and PDMS mold preparation}

All chemicals were purchased from Sigma-Aldrich unless specified otherwise. In order to accurately track tissue development over time, microisland tissues were fabricated and immobilized on acrylated glass coverslips. Circular glass coverslips (21 mm, No. 1, Fisher Scientific) were cleaned using $30 \%$ hydrogen peroxide $\left(\mathrm{H}_{2} \mathrm{O}_{2}\right)$ and $70 \%$ sulfuric acid $\left(\mathrm{H}_{2} \mathrm{SO}_{4}\right)$, followed by thorough ethanol rinsing and air-drying prior to glass acrylation. Cleaned glass coverslips were incubated overnight using diluted acetic acid (9\%), 3-(Trimethoxysilyl) propyl methacrylate, and 200-proof ethanol at $25^{\circ} \mathrm{C}$. After incubation, the acrylated glass coverslips were rinsed in ethanol followed by air-drying.

Polydimethylsiloxane (PDMS) molds were prepared by combining SLYGARD 184 silicone elastomer curing agent and SLYGARD 184 elastomer base (Dow Corning Corporation). PDMS precursor solution was transferred onto a glass slide fixed with $200 \mu \mathrm{m}$ thick spacers on all edges. A second slide was placed on top and the entire assembly was bound together by binder clips. The assembly was transferred into an oven at $70^{\circ} \mathrm{C}$ for $2 \mathrm{~h}$ for curing of the PDMS. The cured PDMS was peeled off the assembly and three cylindrical holes with diameters of 
$6 \mathrm{~mm}$ were punched into the PDMS mold using a cork borer. The PDMS mold and acrylated glass coverslips were soaked in $70 \%$ ethanol for $24 \mathrm{~h}$ followed by complete air-drying under UV-light for at least $24 \mathrm{~h}$ to ensure complete sterilization. Before use in cell encapsulation, the PDMS mold with three cylindrical holes for tissue production was placed on the circular, acrylated glass coverslips and pressed down firmly to prevent leakage.

\section{PEG-fibrinogen synthesis and precursor preparation}

PEG-fibrinogen was prepared as previously described ${ }^{18}$. First, poly(ethylene glycol)-diacrylate (PEG-DA) was prepared by reacting linear PEG-OH (10 kDa) with acryloyl chloride and triethylamine. The product was precipitated in ice-cold diethyl ether, followed by vacuum drying for $48 \mathrm{~h}$. Degree of acrylation was quantified by proton ${ }^{1} \mathrm{H}$ NMR.

For PEG-fibrinogen synthesis, tris(2-carboxyethyl) phosphine hydrochloride (TCEP$\mathrm{HCl}$ ) was combined with $7 \mathrm{mg} / \mathrm{ml}$ fibrinogen in PBS with $8 \mathrm{M}$ urea (1.5:1 TCEP to fibrinogen molar ratio). Next, for PEGylation of fibrinogen, PEG-DA was reacted with fibrinogen (4:1 molar ratio) for $3 \mathrm{~h}$, precipitated in acetone and dissolved in PBS with $8 \mathrm{M}$ urea. The reacted PEG-fibrinogen was dialyzed against PBS at $4^{\circ} \mathrm{C}$ for $48 \mathrm{~h}$ followed by lyophilization. To characterize the PEGylated product, fibrinogen content was measured using Pierce BCA assay (Thermo Scientific).

Lyophilized PEG-fibrinogen powder was re-dissolved in PBS to obtain a final fibrinogen concentration of $10 \mathrm{mg} / \mathrm{ml}$. PEG-fibrinogen precursor solution was prepared by combining PEG-fibrinogen with 1.5\% triethanolamine (TEOA), $3.96 \mu \mathrm{l} / \mathrm{ml} \mathrm{N}$-vinyl pyrrolidone (NVP), and $10 \mathrm{mM}$ eosin Y (Fisher Scientific) photoinitiator (in PBS) ${ }^{19}$. 


\section{HiPSC dissociation and 3D-dhECT microisland formation}

HiPSCs were dissociated using Versene (cluster hiPSC encapsulation for IMR90-1 and 19-9-11 hiPSC lines) or Accutase (single IMR90-1 hiPSC encapsulation, Innovative Cell Technologies) to form 3D developing human engineered cardiac tissue (3D-dhECT) microislands (day -3). Cluster or single hiPSCs were resuspended in mTeSR-1 medium and centrifuged for $5 \mathrm{~min}$ at 200 g. The supernatant was aspirated using a glass Pasteur pipette and complete aspiration was insured through inversion of the tube without disturbing the cell pellet. Cluster or single hiPSCs were resuspended uniformly at a density of $55 \pm 8.5 \times 10^{6} \mathrm{hiPSCs} / \mathrm{ml}$ of PEG-fibrinogen precursor solution using a wide orifice pipette tip. $10 \mu 1$ of this mixture was added to each of the three cylindrical holes in the PDMS mold on acrylated glass coverslips and crosslinked using visible light (intensity of $48 \mathrm{~mW} / \mathrm{cm}^{2}$ at a distance $3 \mathrm{~cm}$ away) for $1 \mathrm{~min}$. The PDMS mold surrounding the three crosslinked hydrogels (3D-dhECT microislands) was then carefully detached and the acrylated glass coverslip with covalently coupled microislands was transferred to a 12-well plate (three tissues per well) and cultured in $2 \mathrm{ml} \mathrm{mTeSR}-1$ medium supplemented with $5 \mu \mathrm{M}$ ROCK inhibitor for $24 \mathrm{~h}$ (day -3 ). On the two days following encapsulation (day -2 , day -1), 3D-dhECT microislands were cultured in mTeSR-1 medium with daily medium exchange. On the third day post-encapsulation (day 0), cardiac differentiation was initiated. All encapsulations resulted into successfully contracting cardiac tissues.

\section{D monolayer differentiation of hiPSCs}

For 2D monolayer differentiation of hiPSCs (IMR90-1 hiPSC line), the composition of the media and timeline of differentiation was based on a previously published method ${ }^{8} ; 2 \mathrm{D}$ differentiating monolayers were used as controls. Briefly, hiPSCs were dissociated using Accutase, resuspended 
in mTeSR-1 medium, counted, and centrifuged. HiPSCs were seeded at $1 \times 10^{6}$ hiPSCs/well in a Matrigel coated 6-well plate with $4 \mathrm{ml}$ mTeSR-1 medium $+5 \mu \mathrm{M}$ ROCK inhibitor for $24 \mathrm{~h}$ (day -4). From day -3 until day 0, mTeSR-1 medium was replaced daily. On day 0 of differentiation, medium was changed to $4 \mathrm{ml}$ RPMI/B27 without insulin (Life Technologies) + $12 \mu$ M CHIR99021 (Selleckchem) for $24 \mathrm{~h}$. Medium was changed to $4 \mathrm{ml}$ RPMI/B27 without insulin for an additional $48 \mathrm{~h}$. On day 3, $2 \mathrm{ml}$ RPMI/B27 without insulin and $5 \mu \mathrm{M}$ IWP2 (Tocris) were combined with $2 \mathrm{ml}$ old RPMI/B27 without insulin ("combined medium") and cells were cultured until day 5, when medium was changed back to RPMI/B27 without insulin. On day 7 and successively every three days, medium was replaced with RPMI/B27 (Life Technologies).

\section{D cardiac differentiation of cluster and single hiPSCs in PEG-fibrinogen hydrogels}

Cluster and single encapsulated hiPSCs underwent differentiation following the same protocol used for the 2D monolayer differentiation of hiPSCs. On day 0 of differentiation, medium was changed from mTeSR-1 to $2 \mathrm{ml} \mathrm{RPMI/B27}$ without insulin $+12 \mu$ M CHIR99021 per well. After $24 \mathrm{~h}$ (day 1), medium was changed to $2 \mathrm{ml}$ RPMI/B27 without insulin. On day 3 of differentiation, medium was replaced with $1 \mathrm{ml}$ fresh RPMI/B27 without insulin, $5 \mu \mathrm{M}$ IWP2, and $1 \mathrm{ml}$ old RPMI/B27 without insulin and cultured for an additional $48 \mathrm{~h}$. On day 5, medium was switched back to $2 \mathrm{ml} \mathrm{RPMI/B27}$ without insulin and followed by $2 \mathrm{ml} \mathrm{RPMI/B27} \mathrm{medium}$ on day 7 , medium being replaced thereafter every three days. 


\section{HiPSC viability and immunofluorescence}

HiPSC viability on day -2 ( $24 \mathrm{~h}$ post-encapsulation) was assessed using a LIVE/DEAD® viability kit (Molecular Probes) following manufacturer's instructions. Confocal Z-stacks (step size $=5 \mu \mathrm{m}$ ) were taken through the entire tissue thickness at several randomly selected locations within each 3D-dhECT microisland $(n=3)$ using a Nikon A1R laser-scanning confocal microscope and NIS Elements software (Nikon). To assess 3D-dhECT protein expression of proliferation markers proliferating cell nuclear antigen (PCNA) and Ki67, cardiac markers cardiac troponin $\mathrm{T}(\mathrm{cTnT})$ and sarcomeric $\alpha$-actinin $(\alpha \mathrm{SA})$, and gap junction protein connexin 43 (Cx43), tissue samples were prepared for immunofluorescence. To assess the area and circularity of single CMs, dissociated 3D-dhECT cells were immunostained using aSA and Caveolin 3 (Ttubules). First, samples were fixed using methanol for PCNA, 4\% paraformaldehyde (Electron Microscopy Sciences) for Ki67, cTnT, $\alpha \mathrm{SA}$, and Caveolin 3, or 50/50 ice-cold acetone/ethanol for Cx43. Fixed tissues and dissociated cells were permeabilized with PBS-T (PBS with 1\% bovine serum albumin (BSA) and $0.2 \%$ Triton X-100) and blocked (3\% fetal bovine serum (FBS, Atlanta Biologicals) in PBS). Samples were consecutively incubated in primary and secondary antibody (Table S2). All primary and secondary antibodies were applied for at least 24 hours at $4^{\circ} \mathrm{C}$. Cell nuclei were stained with 4',6-diamidino-2-phenylindole (DAPI, Molecular Probes). All fluorescently labeled samples were visualized using a Nikon A1si confocal microscope.

For subsequent characterization studies and comparisons to 2D monolayers, cluster encapsulated 3D-dhECTs were used. 


\section{Tissue area growth}

Throughout the initial stages of hiPSC encapsulation, images of entire tissues from both hiPSC lines were acquired daily at low magnification using a phase contrast microscope (Ti Eclipse, Nikon) equipped with an Andor Luca S camera. Tissue edges were identified and the lateral surface area of 3D-dhECTs was analyzed in ImageJ with standard analysis plugins $(n=3-4$ tissues per hiPSC line). Tissue growth was based on normalized day 0 tissue surface area.

\section{Flow cytometry}

On day 20, 2D monolayers were washed with PBS and incubated in $0.25 \%$ trypsin (EDTA, Mediatech) at $37^{\circ} \mathrm{C}$ for $5 \mathrm{~min}$. Age-matched 3D-dhECTs from both hiPSC lines were washed with PBS followed by $2 \mathrm{~h}$ incubation at $37^{\circ} \mathrm{C}$ on a rotator (Boekel Orbitron Rotator, Model 260250, Boekel Scientific) with collagenase Type $2(1 \mathrm{mg} / \mathrm{ml}$, Worthington) in $120 \mathrm{mM} \mathrm{NaCl}$, $5.4 \mathrm{mM} \mathrm{KCl}, 5 \mathrm{mM} \mathrm{MgSO}$, $5 \mathrm{mM}$ Na-pyruvate, $20 \mathrm{mM}$ glucose, $20 \mathrm{mM}$ taurine, and $10 \mathrm{mM}$ HEPES (pH 6.9) supplemented with $30 \mu \mathrm{M} \mathrm{CaCl}_{2}$, followed by incubation in $0.25 \%$ trypsin (EDTA) at $37^{\circ} \mathrm{C}$ for $5 \mathrm{~min}$. All cells (in 2D monolayers and 3D-dhECTs) were then singularized by pipetting (using a $1000 \mu$ l pipette), transferred to a centrifuge tube with RPMI20 medium (RPMI 1640 medium with 20\% FBS) and centrifuged for 5 min at $200 \mathrm{~g}$. The supernatant was removed and the cell pellet was resuspended in 4\% paraformaldehyde and incubated for 20 min at $25^{\circ} \mathrm{C}$. Cells were centrifuged for $5 \mathrm{~min}$ at $200 \mathrm{~g}$, supernatant was aspirated and the cell pellet was resuspended in $90 \%$ cold methanol and incubated at $4^{\circ} \mathrm{C}$ for $15 \mathrm{~min}$. The fixed cells were blocked with 5\% BSA in PBS for 5 min and centrifuged for 5 min at $200 \mathrm{~g}$. After washing two more times with 5\% BSA in PBS, cells were incubated in $100 \mu$ primary antibody (Table S2) diluted in $0.5 \%$ BSA and $0.1 \%$ Triton X-100 in PBS. To analyze CMs, proliferating cells, and 
fibroblasts, the primary antibody combinations cTnT/Ki67 and cTnT/P4HB were chosen. After incubation at $4^{\circ} \mathrm{C}$ overnight, cells were washed with $0.5 \%$ BSA and $0.1 \%$ Triton X-100 in PBS, which was repeated twice. Cells were further incubated in $100 \mu 1$ secondary antibody (Table S2) diluted in $0.5 \%$ BSA and $0.1 \%$ Triton X-100 in PBS for 30 min at room temperature, protected from light. Finally, cells were washed with 0.5\% BSA and 0.1\% Triton X-100 in PBS three times and resuspended for analysis in $500 \mu 15 \%$ BSA in PBS. Samples were run on a BD Accuri C6 (BD Biosciences) and were analyzed using FlowJo V10.

\section{Reverse transcription quantitative PCR}

Total RNA was extracted from hiPSCs, 2D monolayers, and 3D-dhECTs on days 0, 10, 20, and 30 of differentiation ( $n=3$ independent differentiations) using Nucleospin RNA kit (Macherey-Nagel). Reverse transcription quantitative PCR (RT-qPCR) was performed using SuperScript III Platinum One-Step RT-qPCR kit (Invitrogen) in conjunction with Taqman probes (Integrated DNA Technologies). Equal amounts of RNA $(50 \mathrm{ng} / 19 \mu \mathrm{l})$ were used for each measurement. The RT-qPCR protocol consisted of 1 cycle at $50^{\circ} \mathrm{C}(15 \mathrm{~min}), 1$ cycle of $95^{\circ} \mathrm{C}$ (3 min), 45 cycles of $95^{\circ} \mathrm{C}(15 \mathrm{~s})$ and $55^{\circ} \mathrm{C}(30 \mathrm{~s})$. Gene expression levels were normalized to the housekeeping gene GAPDH using the $2-\Delta \mathrm{C}_{\mathrm{t}}$ method. Duplex RT-qPCR was used for Oct4, $M Y L 2 v$, and $C x 43$ genes; $\alpha M H C, \beta M H C$, and $G A P D H$ were quantified separately (Table S3).

\section{Frequency of contraction}

Video recordings of spontaneously contracting 3D-dhECTs were acquired on a phase contrast microscope (Ti Eclipse, Nikon) using a high speed camera (Andor Luca S) to determine frequency of contraction. Number of contractions per minute at early (day 8-11), intermediate 
(day 20-25), late (day 30-33, $n=3$ independent differentiation batches), and long-term (days 50,60, and 90, $n=2$ tissues) time points were analyzed using NIS Elements and ImageJ software. Contractility differences between single and cluster encapsulated hiPSCs were determined by video analysis of the relative changes in transmitted light intensity of spontaneously contracting cardiac tissues on day 14 of differentiation.

\section{Sarcomere alignment and spacing in 3D-dhECT CMs}

Throughout the differentiation process, sarcomere alignment of days 20, 30, and 124 aSA-stained cardiac tissues was analyzed using ImageJ software version $1.48 \mathrm{q}(\mathrm{NIH})$ in affiliation with the fast Fourier transform (FFT) analysis tool. Images were imported into ImageJ, and sarcomere pattern formation over time was assessed by increasing periodicity, alignment, and pattern convergence in the FFT output spectra. Sarcomere alignment and spacing was also determined by manually drawn linear paths along visible sarcomeres. In addition to sarcomere alignment, day $124 \alpha \mathrm{SA}$-stained CMs were used to quantify sarcomere spacing; for this, manually drawn linear paths along well-defined sarcomeres $(n=200 \mathrm{CMs})$ were used to collect an intensity profile for each chosen $\mathrm{CM}$ where distances between peaks were analyzed using Microscoft Excel. Sarcomeres chosen for alignment and spacing were selected based on continuity of sarcomeres in a single field of view.

\section{D-dhECT CM size, circularity, length-to-width ratio and Caveolin 3 immunofluorescence staining}

For size and circularity measurements, day 52-60 tissues were dissociated into single cells (see tissue dissociation section in Flow Cytometry) and re-plated onto fibronectin coated PDMS 
coverslips. After three days, cells were immunofluorescently stained and imaged. Cells were analyzed for their cell area and circularity using ImageJ software with standard analysis plugins ( $n=32 \mathrm{CMs})$. These samples were also used for $\alpha \mathrm{SA} /$ Caveolin 3 staining. Four month old 3DdhECTs were enzymatically dissociated and seeded onto fibronectin-coated well plates. $24 \mathrm{hrs}$ after dissociation, phase contract images were taken of three separately dissociated tissues. Length and width of 60 cells were measured using ImageJ and the ratio was calculated. Cell clusters of two or more cells were excluded for this analysis.

\section{Calcium handling}

To immobilize cells for proper calcium transient acquisition, glass coverslips (21 mm, No. 1, Fisher Scientific) were coated with PDMS using a WS-400-6NPP spin coater (Laurell Technologies Corporation). Briefly, SLYGARD 184 silicone elastomer curing agent was mixed with SLYGARD 184 elastomer base (Dow Corning Corporation) at a ratio of 1:10, applied on the glass coverslips and evenly spin-coated to obtain PDMS coated coverslips. These were cured at $60^{\circ} \mathrm{C}$ for several hours, sterilized using $70 \%$ ethanol, and then dried under sterile conditions for at least $24 \mathrm{~h}$. In order for successful single CM attachment, $25 \mu \mathrm{g} / \mathrm{ml}$ fibronectin in ice-cold ultrapure water was applied on PDMS coated coverslips and incubated for at least one hour at room temperature.

Day 14 2D monolayers and 3D-dhECTs were dissociated using 0.25\% trypsin (EDTA) at $37^{\circ} \mathrm{C}$ for 5 and $8 \mathrm{~min}$, respectively. Cells were singularized by pipetting, added to RPMI20 medium $^{20}$, and centrifuged for $5 \mathrm{~min}$ at $200 \mathrm{~g}$. Singularized cells were resuspended in RPMI20 + $5 \mu \mathrm{M}$ ROCK inhibitor and transferred onto fibronectin-coated PDMS-glass coverslips. Cells were incubated for $48 \mathrm{~h}$ to ensure uniform cell attachment. Medium was then switched to 
RPMI/B27 and cells maintained for 3 to 5 days. CM calcium transient recordings were obtained using an IonOptix Myocyte Calcium and Contractility Recording System. Samples were incubated in $5 \mu \mathrm{M}$ Fura-2AM dye (Molecular Probes) in $37^{\circ} \mathrm{C}$ warm Tyrode's solution $(1.8 \mathrm{mM}$

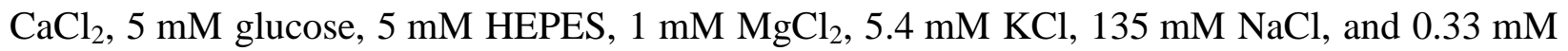
$\mathrm{NaH}_{2} \mathrm{PO}_{4}, \mathrm{pH}$ 7.4) for $30 \mathrm{~min}$. $\mathrm{CMs}$ were paced at frequencies from $0.5-2.0 \mathrm{~Hz}(0.5 \mathrm{~Hz}$ increments) and stimulated at $30 \mathrm{~V}$; maximum capture rate was defined as the highest pacing frequency for which there was a 1:1 correspondence between exogenous pacing and cell response. Calcium transients were recorded 100 frames per second and calcium transient duration at $50 \%$ and $80 \%$ time to baseline was measured. In addition to responses to outside electrical stimuli, spontaneously contracting 3D-dhECT CM response to $0.5 \mu \mathrm{M}$ isoproterenol (Molecular Devices) was examined. Representative calcium transient traces were processed by temporal averaging of five time steps.

\section{Multielectrode array (MEA)}

Day 20 3D-dhECTs were dissociated for $2 \mathrm{hrs}$ in collagenase solution (as previously described for flow cytometry), resuspended in RPMI20 medium supplemented with $5 \mu \mathrm{M}$ ROCK inhibitor, and cultured on a S2 type MEA200/30-Ti-grfor (Multichannel Systems) for at least $24 \mathrm{hrs}$. Spontaneously contracting CMs were perfused with Tyrode's solution at $37{ }^{\circ} \mathrm{C}$ using a MEA system with Multichannel Systems 1060-Inv-BC amplifier. When stabilized, baseline field potential recordings were acquired at a sampling frequency of $10 \mathrm{kHz}$. CMs were exogenously paced at $0.5,1,2$, and $3 \mathrm{~Hz}$. To assess drug response, $1 \mu \mathrm{M}$ isoproterenol was added with a subsequent addition of $1 \mu \mathrm{M}$ propranolol (Molecular Devices). Drugs were washed out to recover the baseline field potential profile. 


\section{Transmission electron microscopy (TEM)}

Day 24 and day 124 3D-dhECTs were fixed in 3\% glutaraldehyde (Electron Microscopy Science) at $4^{\circ} \mathrm{C}$ before shipping to the pathology core at Icahn School of Medicine at Mount Sinai, NY. Tissue samples were sectioned $(50-60 \mathrm{~nm})$ and stained with Uranyl Acetate Solution and Reynold's Lead Citrate Solution. Processed tissue slices were examined using a transmission electron microscope (H-7650, Hitachi High Technologies).

\section{Quantification of sarcomere structure}

The prevalence of H-zones and I-bands were measured to quantify the sarcomere structural features. The numerical ratio of H-zones to sarcomeres, and the ratio of I-bands to Z-lines were analyzed from TEM images from day 124 3D-dhECTs using ImageJ software version $1.49 \mathrm{v}$ (NIH) with the Plot Profile analysis tool. Each image was imported into ImageJ and a linear region of interest was manually drawn across the length of a selected sarcomere; a 25-pixel line width was used to improve signal to noise, with the live plot option allowing real-time evaluation of the gray scale intensity pattern. The variation in gray scale values was used to identify Z-lines (pronounced decrease in the gray scale value), I-bands (pronounced increase in the gray scale value bordering the Z-lines) and H-zones (increase in gray value in the central region between each pair of Z-lines). A total of 101 sarcomeres and 142 z-lines were measured from 3 TEM images at 2-2.5K magnification. 


\section{Statistics}

Results were analyzed from a minimum of three replicates for each experiment using Minitab 16. All values presented are mean \pm SD. Data were compared using one-way analysis of variance (ANOVA) followed by Tukey's test, $P<0.05$ was considered statistically significant.

\section{Results \\ PEG-fibrinogen hydrogels support stem cell survival and proliferation}

HiPSCs are frequently cultured and passaged in multi-cellular clusters, which has been reported to enhance cell viability and maintenance of pluripotency when compared to single cell dissociation ${ }^{21}$. On the other hand, the inherent variability in cluster size might present a challenge for creating highly reproducible 3D-dhECTs from hiPSCs. In the presented study, we established the ability to create 3D tissues using both cluster and single dissociated hiPSCs. In both cases, a cell suspension of $55 \pm 8.5 \times 10^{4}$ hiPSCs per tissue was combined with aqueous PEG--fibrinogen precursor solution and photocrosslinked using visible light to create $200 \mu \mathrm{m}$ thick 3D "microisland" tissues (Fig. 1A). Both cluster and single hiPSCs were uniformly distributed throughout the 3D-dhECT microislands (Fig. 1B, G); tissues formed using single hiPSCs appeared more homogeneous compared to cluster encapsulated hiPSCs (Fig. S1A). HiPSC viability 24 h post-encapsulation (day -2, Fig. 1C, H) was comparable to standard hiPSC passage and culture ${ }^{22}$.

Encapsulated cluster and single dissociated hiPSCs grew and proliferated within the PEG--fibrinogen hydrogels both prior to (day -2 to day 0, Fig. S1A) and following initiation of differentiation (day 0), which resulted in an expanded microisland lateral surface area of $20.1 \pm 8.0 \%$ (IMR90-1 hiPSC line) and 25.5 $\pm 8.0 \%$ (19-9-11 hiPSC line) by day 5 of 
differentiation (Fig. S1B). Cell proliferation on day 10 was observed by immunostaining for proliferating cell nuclear antigen (PCNA, Movie S1), with the highest number of proliferating cells located on the tissue edges (Fig. S1C). During early stages of cardiac differentiation, cluster dissociated hiPSCs continued to grow as aggregates. Cells occupied the entire hydrogel volume quickly (Fig. 1D, F) and tissues exhibited more growth at the edges than in the center. Tissue thickness increased from $\sim 200 \mu \mathrm{m}$ to $300 \mu \mathrm{m}$ between days 3 and 5 , with a dense tissue ring forming around the perimeter of the microisland (Fig. S1D). In comparison, encapsulated single hiPSCs first formed small colonies and then subsequently formed interconnected tissue structures (Fig. 1I, K). 

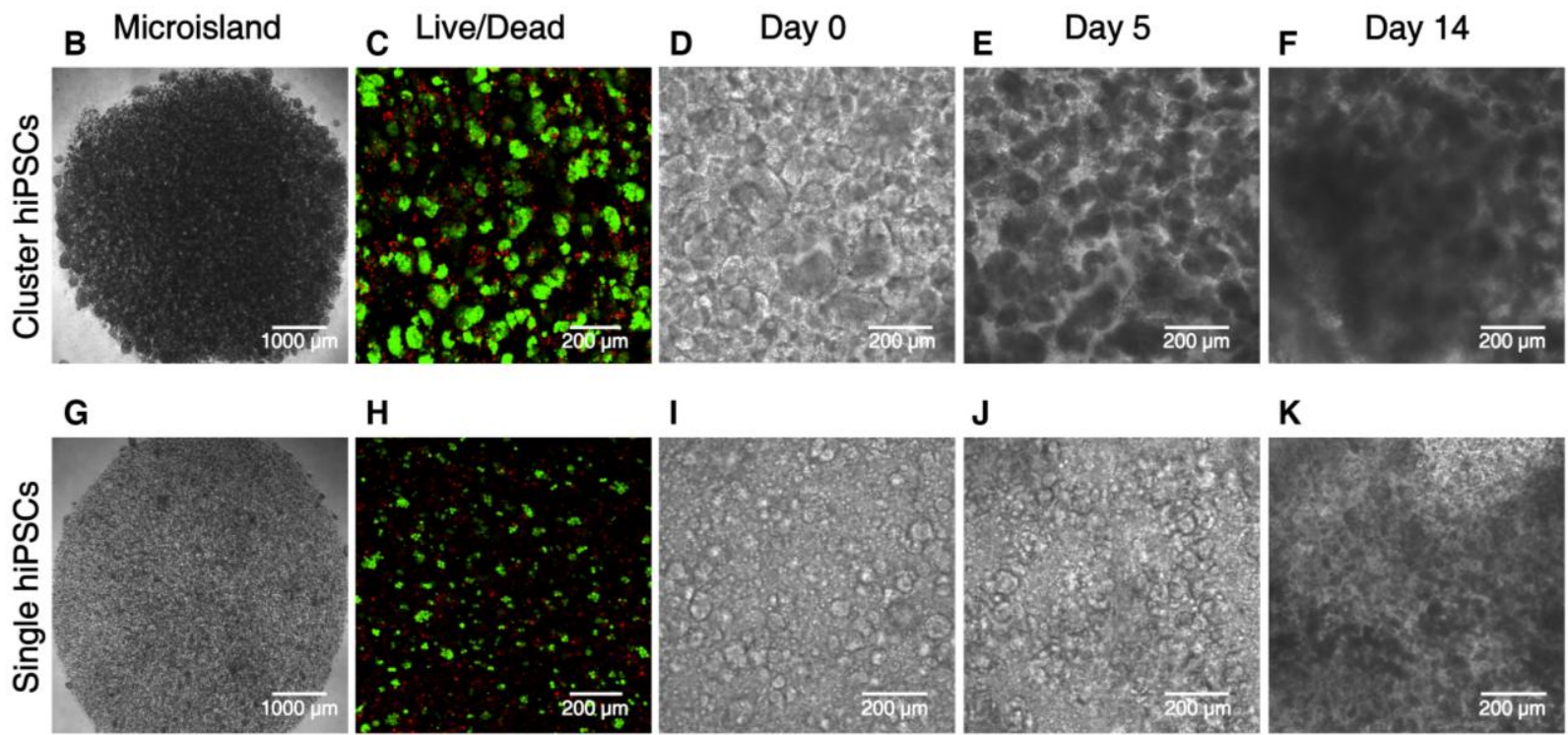

K

Fig. 1. Schematic and progression of hiPSC encapsulation to produce 3D-dhECTs. (A) HiPSCs were combined with aqueous PEG-fibrinogen precursor, added into a PDMS mold (not shown) on acrylated glass, and photocrosslinked using a non-toxic photoinitiator and visible light to form $200 \mu \mathrm{m}$ thick "microisland" tissues. All encapsulated hiPSCs were maintained in their pluripotent state for three days, followed by initiation of cardiac differentiation to produce uniformly contracting 3D-dhECTs. Encapsulated (B) cluster and (G) single hiPSCs formed 
"microisland" tissues (images taken on day 0 of differentiation). (C, H) HiPSCs remained viable (green) $24 \mathrm{~h}$ post-encapsulation ( $n=3$ tissues) and (D-F, I-K) proliferated during early stages of cardiac differentiation. F, K represent Movies S3 and S4.

\section{Encapsulated hiPSCs form uniformly contracting, functional cardiac tissues}

This direct encapsulation and cardiac differentiation process resulted in uniformly contracting cardiac tissues with a high degree of repeatability, while requiring only one cell-handling step. All 3D-dhECTs were observed to spontaneously contract, with contraction initiating consistently on day 6 for the cluster 19-9-11 hiPSC line encapsulations $(n=3$ independent differentiations, Movie S2), day 7 for all cluster IMR90-1 hiPSC line encapsulations ( $>40$ independent differentiations), and between days 9-11 for all single encapsulated hiPSCs ( $\mathrm{n}=3$ independent differentiations), which compares to day 8-9 for control 2D monolayers $(n>20$ independent differentiations). The number of spontaneously contracting areas and synchronicity of contraction increased over time for both cluster and single cell 3D-dhECTs, consistently resulting in essentially uniform contracting tissues by day 14 (Movies S3 and S4). Frequency of spontaneous contraction for cluster 3D-dhECTs was slowest during early differentiation $(0.60 \pm 0.21 \mathrm{~Hz}$, days 8-11) and increased throughout the differentiation process to $1.37 \pm 0.04 \mathrm{~Hz}$ by days $30-33(n=3$ separate differentiations, Fig. S2A). During long-term culture, the spontaneous contraction rate reached its highest frequency $(2.2 \pm 0.1 \mathrm{~Hz})$ on day 50 ( $n=2$ tissues) and then began to decrease, stabilizing at $1.35 \pm 0.05 \mathrm{~Hz}$ at day 90 (Fig. S2A). Frequency of contraction for single cell 3D-dhECTs tended to be slower than for cluster 3DdhECTs $(0.48 \pm 0.50 \mathrm{~Hz}, n=2$ vs. $0.60 \pm 0.21 \mathrm{~Hz})$ during early stages of differentiation, and contractility did not appear to be as strong as that of age-matched cluster 3D-dhECTs (Fig. S2B). 
Cluster hiPSC encapsulation was chosen for all subsequent experiments due to the higher batch-to-batch consistency of cluster 3D-dhECTs, particularly with respect to the time point for initiation of contraction, as compared to single cell 3D-dhECTs.

\section{D-dhECTs demonstrate differentiation efficiency and cardiac gene expression similar to 2D monolayers}

Cardiac differentiation within the 3D-dhECTs resulted in high CM yield and temporal changes in gene expression that were analogous to those in age-matched 2D monolayers. To determine the efficiency of cardiac differentiation within 3D-dhECTs, the percentage of cells expressing cardiac troponin $\mathrm{T}$ (cTnT, cardiac specific marker) was evaluated by flow cytometry and immunofluorescence on day 20. The 3D-dhECTs were composed of $72.5 \pm 3.2 \%$ (IMR90-1 hiPSCs) and $75.65 \pm 1.8 \%$ (19-9-11 hiPSCs) cTnT positive cells, of which $8.4 \pm 0.7 \%$ also expressed the proliferation marker Ki67 (IMR90-1 hiPSCs, Fig. 2A); cardiac differentiation was similar to age-matched 2D monolayers which had $74.3 \pm 4.4 \%$ cTnT positive cells, $26.6 \pm 0.5 \%$ of which also expressed Ki67 (IMR90-1, Fig. 2B). Immunofluorescence of 3D-dhECTs also confirmed the expression of cTnT and Ki67 (Fig. 2C). Of the remaining 3D-dhECT cells, $5.24 \pm 2.72 \%$ were fibroblasts (P4HB positive, Fig. S3) and $2.96 \pm 1.98 \%$ expressed Ki67 (Fig. 2A).

Temporal changes in pluripotency and cardiac gene expression in 3D-dhECTs paralleled that of age-matched control 2D monolayers. Three days post-encapsulation (day 0), expression of the pluripotency gene Oct4 continued to be similar to hiPSCs (day -3) in both culture systems, as assessed by RT-qPCR. By day 10 of differentiation, Oct4 expression had decreased significantly compared to hiPSCs and remained low (Fig. 2D). The decrease in pluripotency was paired with a simultaneous upregulation in cardiac and functional gene expression. MLC2v, an 
early cardiac marker, increased in both 2D monolayers and 3D-dhECTs from day 10 to day 30 of differentiation (Fig. 2E). Cardiac development was also tracked through assessment of $\alpha M H C$ and $\beta M H C$ expression, where $\beta M H C$ is the predominant isoform in the healthy adult human ventricle $^{23} .2 \mathrm{D}$ monolayers and 3D-dhECTs expressed $\alpha M H C$ from day 10 through day 30. Expression of $\alpha M H C$ in 3D-dhECTs did not change significantly between days 10-30 whereas $\beta M H C$ expression increased by day 30 (Fig. 2F, G). This increase in $\beta M H C$ gene expression by day 30 of differentiation suggests that cardiac maturation occurs over time within the 3D-dhECTs, similar to 2D differentiation. Expression of the $C x 43$ gene, which encodes for a gap junction protein important for cardiac function, increased significantly from day 20 to day 30 in 3D-dhECTs and control 2D monolayers and could contribute to maturation of cell-cell junctions between adjacent CMs (Fig. 2H). 
A

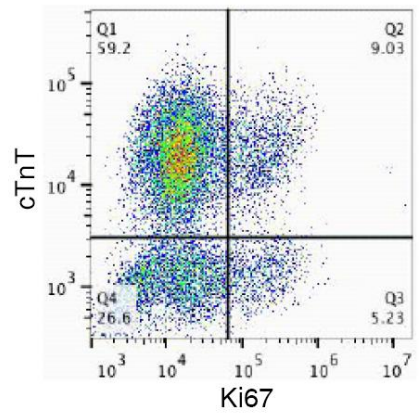

D

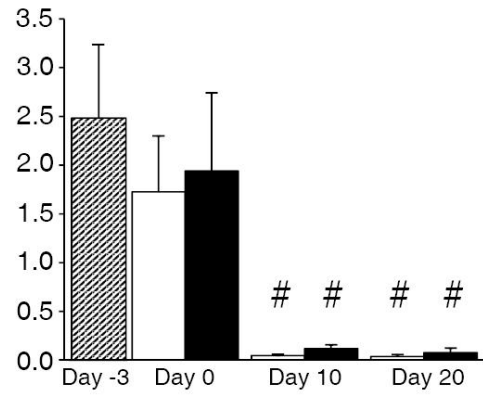

F

aMHC

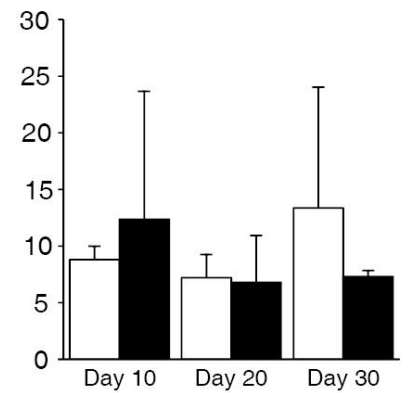

Oct4
B

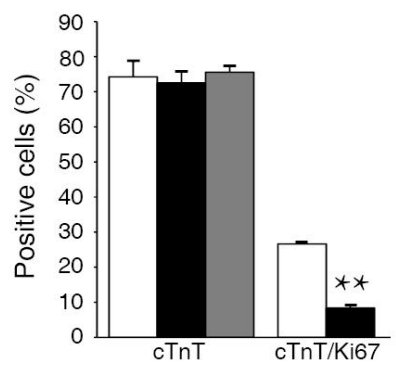

E

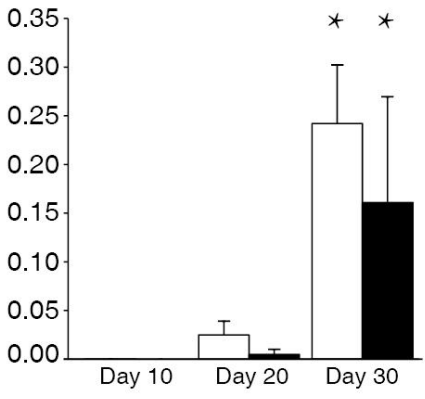

$\beta M H C$

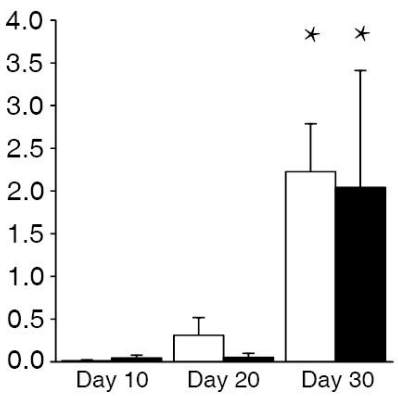

C

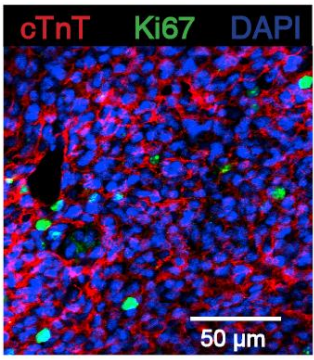

MLC2v

HiPSC

2D IMR90-1 hiPSC

3D IMR90-1 hiPSC

3D 19-9-11 hiPSC

Fig. 2. 3D-dhECTs enabled efficient cardiac differentiation and gene expression. (A) Representative flow cytometry results from day 20 3D-dhECTs. (B) 3D-dhECTs and agedmatched 2D monolayers (control) showed comparable differentiation efficiency on day 20 of differentiation. $n=3-5$ biological replicates per group. Mean \pm s.d. ANOVA $P<0.05$, ** vs. 2D (C) Cardiac marker cTnT and proliferation marker Ki67 were also observed using immunofluorescence staining of day 20 cardiac tissues. (D) Pluripotency gene Oct4 decreased following initiation of differentiation, while cardiac genes (E) $M L C 2 v,(\mathrm{~F}) \alpha M H C,(\mathrm{G}) \beta M H C$, as 
well as $(\mathrm{H})$ the functional gene $C \times 43$ showed trends towards $\mathrm{CM}$ maturation over time. All mRNA levels were normalized to the housekeeping gene GAPDH. $n=3$ biological replicates per group. Mean \pm s.d. ANOVA $P<0.05$, \# vs hiPSCs and day $0 ; *$ vs. earlier time point.

\section{D-dhECT CMs exhibit similar calcium handling to CMs from 2D cardiac monolayers}

In addition to 3D-dhECTs demonstrating high $\mathrm{CM}$ yields and appropriate cardiac gene expression profiles similar to age-matched 2D monolayers, CMs from both systems had similar contractile function and calcium handling properties, which are critical features of differentiating $\mathrm{CMs}^{24}$. To study these properties, CMs were enzymatically dissociated from 3D-dhECTs and 2D monolayers at day 14. Isolated CMs continued to contract spontaneously and also responded to exogenous pacing, exhibiting a maximum 1:1 capture rate of $1.5 \mathrm{~Hz}$ for both 3D- and 2Ddifferentiated CMs Calcium transient durations for 3D-dhECT CMs were similar to those of control 2D monolayer CMs (Fig. 3A-C). Calcium transient duration decreased in response to increased pacing frequency for both groups of $\mathrm{CMs}$, mimicking the frequency-dependent physiological response of healthy myocardium ${ }^{25}$. CMs also responded appropriately to treatment with isoproterenol $(0.5 \mu \mathrm{M}$ for $3 \mathrm{~min})$, a $\beta$-adrenergic agonist; the frequency of spontaneous contraction increased by 1.2-fold and calcium transient duration shortened significantly (Fig. 3D, E). The frequency of 3D-dhECT spontaneous contraction slowed significantly after the addition of the $\beta$-adrenergic antagonist propranolol. First, $1 \mu \mathrm{M}$ isoproterenol was administered to whole tissues, which caused a significant increase in contraction frequency. As previously observed from isolated cells ${ }^{26,27}$, the addition of propranolol reversed this initial increase in beats per minute, demonstrating that our 3D-dhECTs respond to beta agonists and antagonists (Fig. 3F). These responses to exogenous pacing and $\beta$-adrenergic agonist and antagonist were further verified using MEA analysis (Fig. S4). Dissociated day 20 3D-dhECTs responded to outside 
A
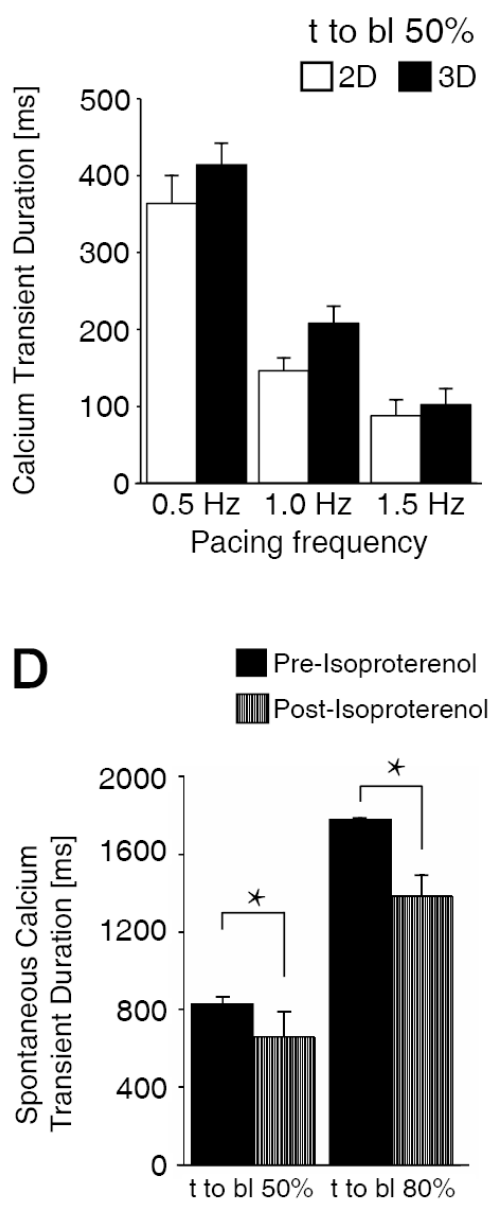

B

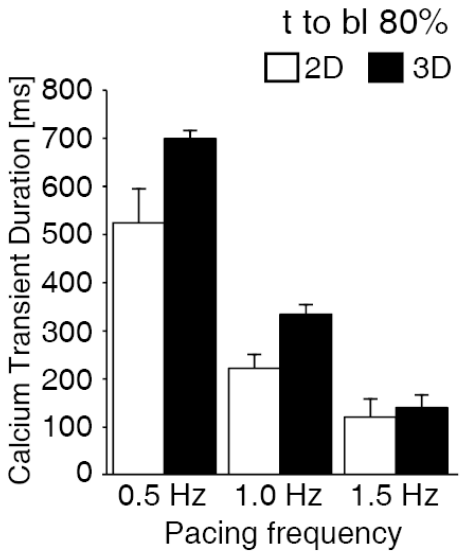

E
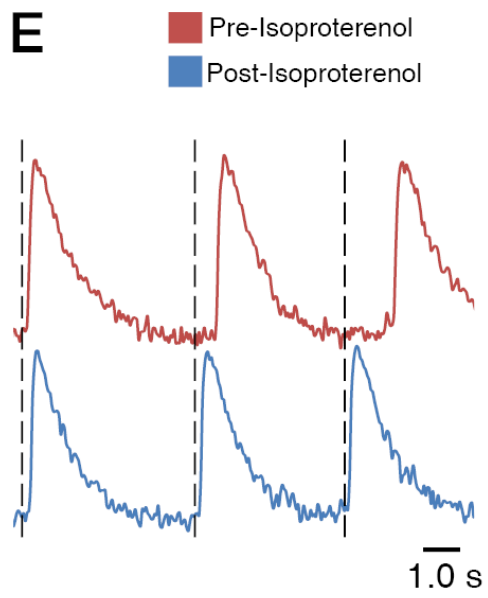

C $2 \mathrm{D} 1.0 \mathrm{~Hz}$
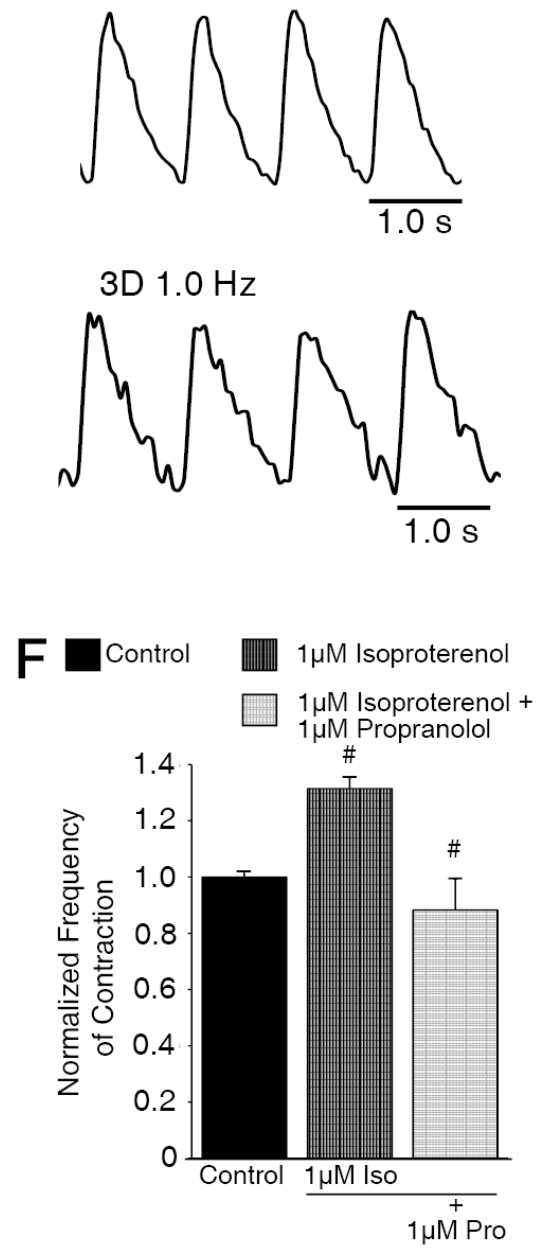

Fig. 3. 3D-dhECT CMs responded to exogenous pacing and beta adrenergic agonist and antagonist drug treatment. During exogenous pacing, time to baseline (t to bl) (A) 50\% and (B) $80 \%$ were similar for $2 \mathrm{D}$ and $3 \mathrm{D}$ cultured CMs (day 14). (C) Representative calcium transient traces of $2 \mathrm{D}$ and $3 \mathrm{D}$ cultured cells at $1 \mathrm{~Hz}$ pacing frequency. (D) Addition of $0.5 \mu \mathrm{M}$ isoproterenol shortened spontaneously contracting 3D-dhECT CM calcium transient t to bl 50\% and $80 \%$, suggesting that the chronotopic response to $\beta$-adrenergic signaling is operational. (E) In these early stage 3D-dhECT CMs, isoproterenol increased the rate of spontaneous contraction. 
$n=3$. Mean \pm s.d. ANOVA $P<0.05$, * vs. Pre-Isoproterenol. (F) Rate of 3D-dhECT spontaneous contraction increased after the addition of isoproterenol $(1 \mu \mathrm{M})$ and decreased after subsequent addition of the $\beta$-adrenergic antagonist propranolol $(1 \mu \mathrm{M})$. \# vs. earlier condition.

\section{D-dhECT CMs develop mature structural features over time}

3D-dhECTs were able to be maintained long-term, with CMs developing aligned and more defined sarcomeres over time and establishing mature ultrastructural features. Cells within the 3D-dhECTs self-aligned, particularly on tissue edges, by day 30 of differentiation; immunofluorescence staining for the cardiac marker sarcomeric $\alpha$-actinin ( $\alpha$ SA) on days 10, 20, and 30 revealed progressive sarcomere development with better defined and aligned sarcomeres by day 30 of differentiation (Fig. 4A). This result was unexpected; extrinsic stimuli, such as mechanical stretching ${ }^{10,28-30}$ or electrical pacing ${ }^{10,31,32}$, have often been used to enhance the ability of CMs to mature, align, and uniformly contract within engineered cardiac tissues assembled using pre-differentiated SC-CMs. However, the temporal upregulation of cardiac gene expression and increased organization of cardiac proteins suggested $\mathrm{CM}$ maturation within 3D-dhECTs was progressing spontaneously, which led us to further investigate CM organization and ultrastructural development during long-term tissue culture. Based on 2D fast Fourier Transform (FFT) analysis of immunofluorescence images from day 20, 30, and 124 3D-dhECTs, sarcomeres became more defined over time (Fig. S5A-C). Some discrete sarcomere structure was observed during early stages of differentiation (day 20); by day 124 3D-dhECT CMs had aligned, organized, well-defined sarcomeres with an average relaxed length of $1.8 \pm 0.1 \mu \mathrm{m}$ (Fig. S5D, $n=200$ cells), similar to mature human CM sarcomere structure $^{12,33}$. Following extended in vitro culture (day 52-60), tissue dissociation into single CMs revealed a wide range 
of cell sizes $\left(400-5,800 \mu \mathrm{m}^{2}\right.$, mean $\left.=2,163 \mu \mathrm{m}^{2}\right)$ and circularities $(0.10-0.86$, mean $=0.43)($ Fig. 4B, C). When maintained long-term, 3D-dhECTs CMs showed features of mature CMs (Fig. S6A) and 3D-dhECTs continued to have higher cell density on the tissue edges with CMs growing outward from the tissue onto the supporting substrate (Fig. S6B, C). Cellular organization within the long-term cultured 3D-dhECTs (day 124) exhibited large cell nuclei (Fig. 4D) and developed characteristics of mature electromechanically anisotropic cardiac tissues, including aligned CMs with the gap junction protein connexin $43(\mathrm{Cx} 43)$ located on the transverse ends (Fig. 4E) of adjoining cells. When dissociated, 3D-dhECT CMs exhibited an elongated, anisotropic morphology with a length-to-width ratio of $6.2 \pm 2.2(n=60 \mathrm{CMs})$, similar to morphologies expected in mature $\mathrm{CMs}^{3,32,34}$. 


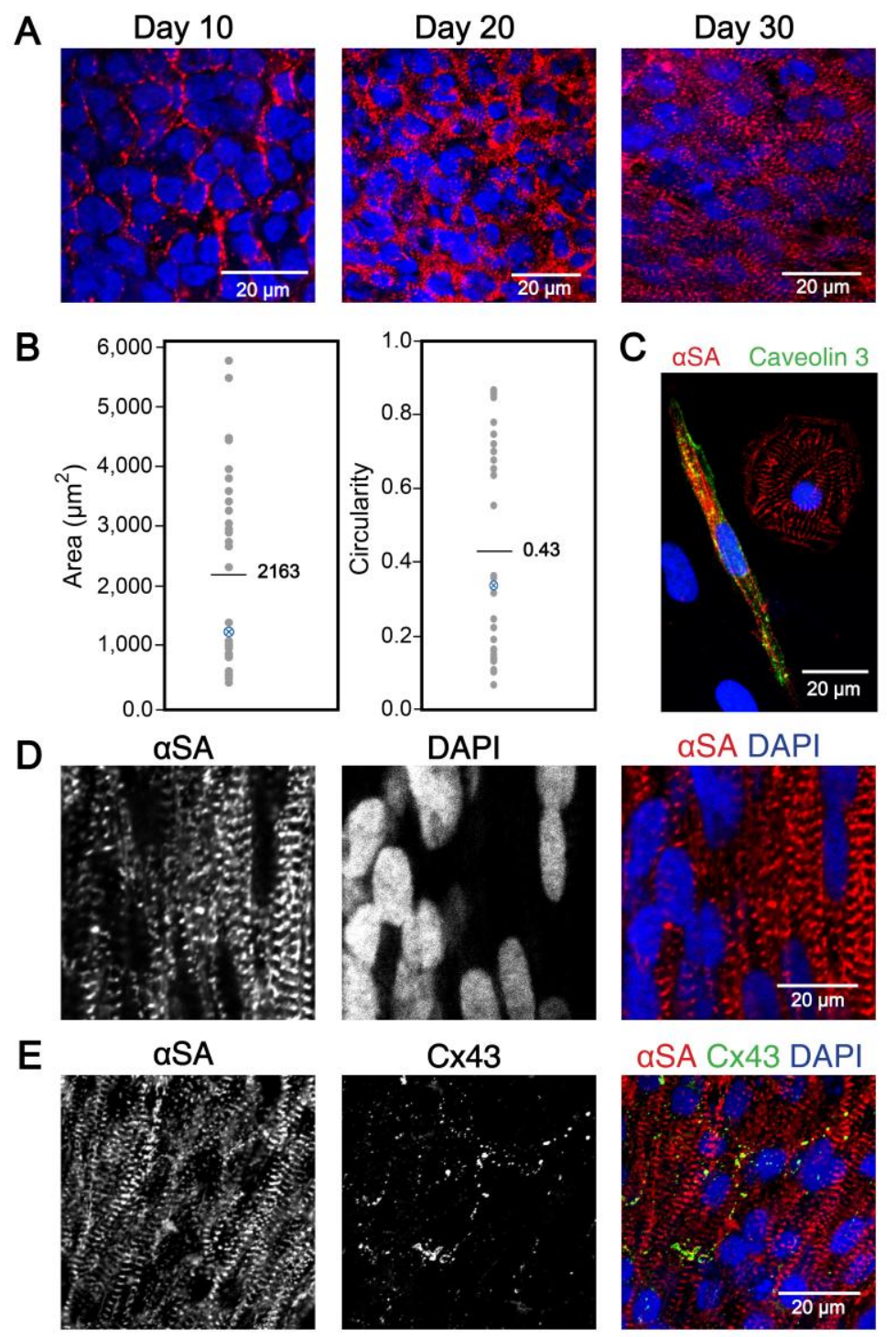

Fig. 4. Ontogenetic tissue development generating well-defined and aligned sarcomeres over time. (A) Sarcomere definition and alignment became more pronounced with culture time. Immunofluorescence staining with cardiac marker $\alpha$ SA on days 10, 20, and 30 of differentiation showed increased sarcomere definition and alignment in 3D-dhECT CMs. (B) Day 52-60 dissociated 3D-dhECT CM area and circularity ranged from 400-5,800 $\mu \mathrm{m}^{2}\left(\right.$ mean $\left.=2,163 \mu \mathrm{m}^{2}\right)$ and $0.10-0.86$ (mean $=0.43)$, respectively $(n=32)$. Blue highlighted data points indicate medians. (C) Representative day 52 dissociated CMs stained with $\alpha$ SA (red) and Caveolin 3 (green) for T-tubule development. Long-term cultured 3D-dhECT (day 124) CMs (D) developed 
highly aligned sarcomeres and contained large and elongated cell nuclei. (E) Additionally, these CMs expressed $\mathrm{Cx} 43$ on their transverse ends between adjoining cells.

To further investigate 3D-dhECT CM maturation, cardiac ultrastructural features were visualized using TEM. Day 24 cardiac tissues showed the presence of Z-lines and mitochondria (Fig. 5A), reflecting early developmental stages of functional CMs. 3D-dhECTs maintained long-term (day 124) were composed of CMs with ultrastructural features approximating those of mature CMs. TEM images revealed numerous mitochondria, and myofibrils with well-defined sarcomeric Z-lines, I-bands, and H-zones, with a H-zone to sarcomere ratio of 0.257 and an Iband to Z-line ratio of 0.669 (Fig. S6D). Other features of 3D-dhECT CMs included intercalated discs on the transverse edges of CMs with adjacent gap junctions (Fig. 5B), caveolae in the plasma membrane, and presence of basement membrane. Most notably, 3D-dhECT CMs exhibited transverse tubules (T-tubules) which were structurally aligned with Z-lines (Fig. 5C); up until now, T-tubules have only been observed in primary CMs isolated from postnatal and adult mammalian hearts ${ }^{35}$, but have not been reported in any other in vitro human SC-CM study $^{36-38}$. 


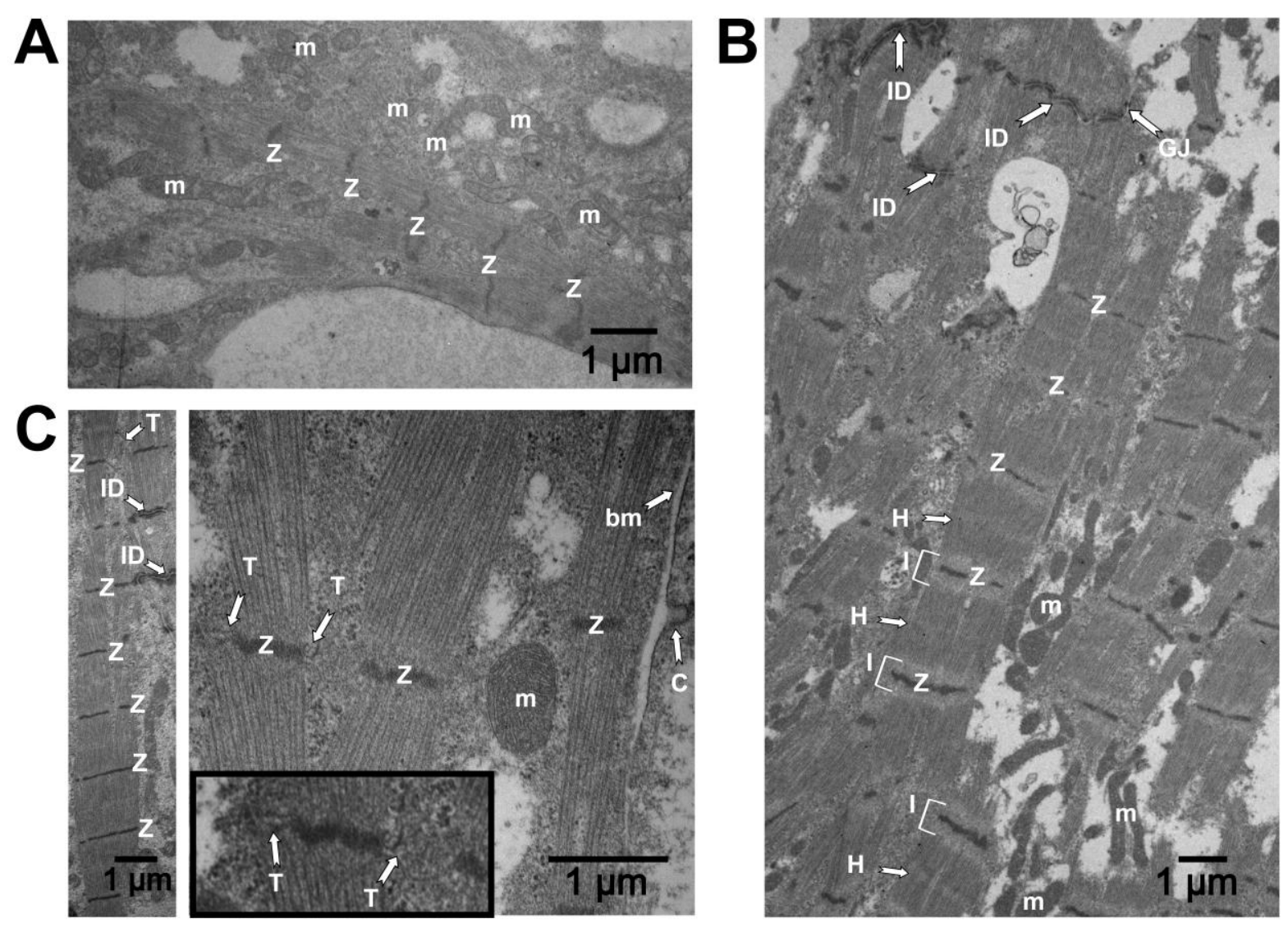

Fig. 5. Ontomimetic environment resulted in 3D-dhECT CMs exhibiting mature ultrastructural features. (A) Day 24 3D-dhECT CMs developed first characteristics of a muscle cell including mitochondria (m) and Z-lines (Z). (B) Ultrastructural images of 124 day old 3D-dhECT CMs showed sarcomere structures, including Z-lines (Z), I-bands (I), H-zones (H), intercalated discs (ID), gap junctions (GJ), and mitochondria (m). (C) Additionally, CMs contained caveolae (C) adjacent to basement membrane (bm), mitochondria with well-defined cristae, and T-tubules (T) adjacent to Z-lines, a key component of functional mature CMs. Insert: magnified view processed to highlight T-tubules. 


\section{Multiple geometries support cardiac tissue formation through direct hydrogel encapsulation}

This straightforward 3D-dhECT formation process was extended to fabricate cardiac tissues across multiple size scales and geometries, demonstrating our ability to create tissues exploitable for a wide range of possible applications (Fig. 6). Furthermore, immobilization of the 3D-dhECTs through covalent attachment to the glass coverslips was found not to be necessary for cardiac tissue formation; 3D-dhECTs in suspension culture also formed contracting tissues that were consistently maintained for multiple months. In addition to the immobilized microislands (Fig. 6A) described in-depth above, tested geometries included macrotissues (Fig. 6B) and microspheres (Fig. 6C). Macrotissues (Fig. 6B) of varying lengths, thicknesses of 800-900 $\mu \mathrm{m}$ and widths greater than $2 \mathrm{~mm}$ were formed and cultured in suspension. Analogous

to the microislands, contracting areas were first observed in the macrotissues on day 7 of differentiation, resulting in robust, uniform contraction early in the differentiation process (day 12) and appearing strong over the entire culture period (Movie S5). Similarly, suspension culture of 3D-dhECT microspheres of diameter $280 \pm 70 \mu \mathrm{m}(n=25$, Fig. 6C) resulted in uniformly contracting spheres that again could be maintained over extended time periods (Movie S6). Finally, all cardiac tissue geometries were successfully dissociated into individual CMs (Fig. 6D), enabling subsequent single-cell experiments or collection and re-suspension as might be required for delivery as a cell therapy. 

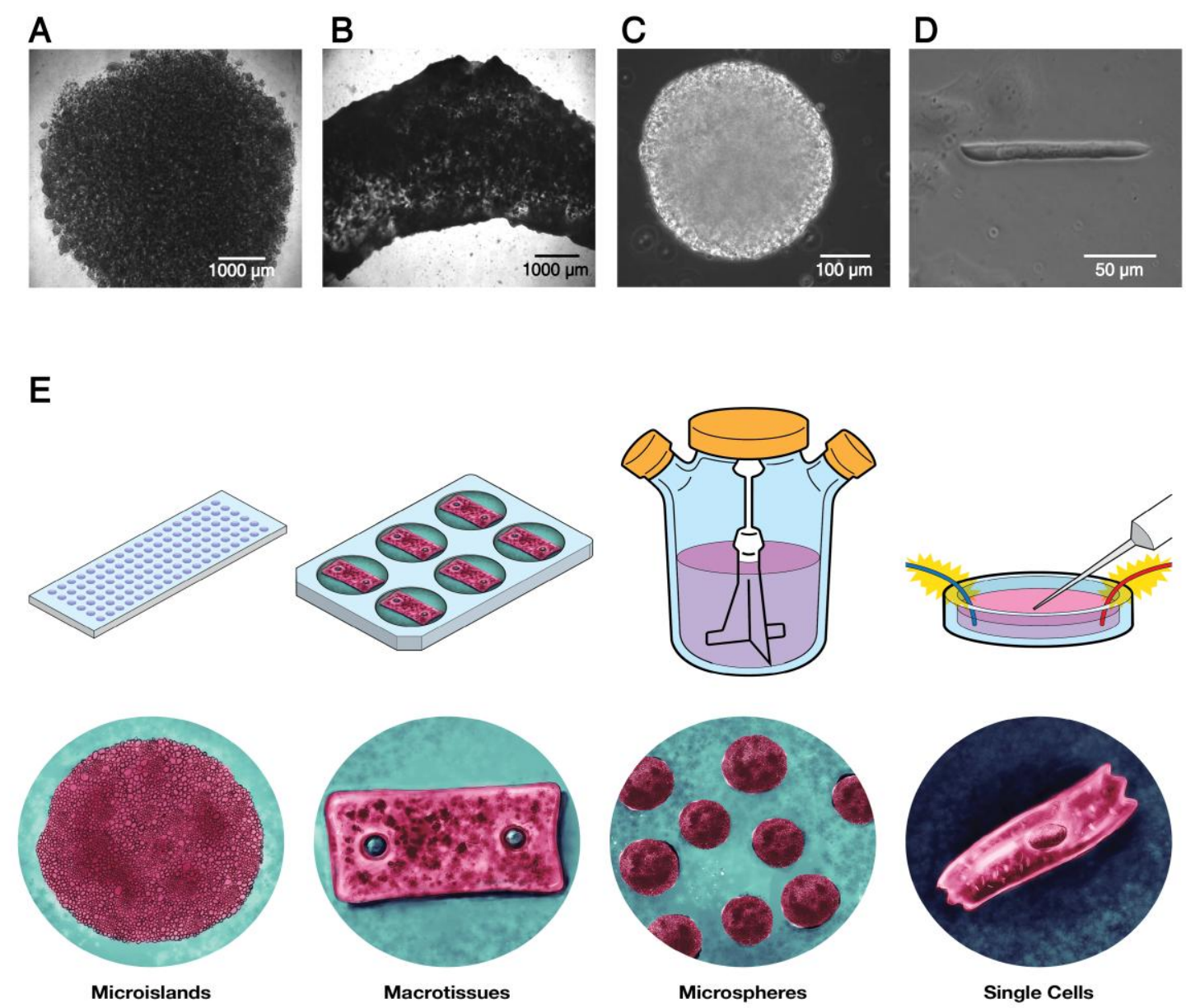

Fig. 6. Using this single cell-handling approach, different tissue sizes and geometries of 3DdhECTs can be formed. Uniformly contracting tissues, in addition to (A) immobilized microislands, included: (B) macrotissues and (C) microspheres, all of which were able to be used to obtain (D) 3D-dhECT-dissociated single CMs. (E) Tissue sizes and geometries can be varied based on desired future applications, e.g., microislands for high-throughput drug-screening, macrotissues for large-scale mechanical testing and cardiac patches, injectable cardiac tissue spheroids, or single CMs post-tissue digestion for automated patch clamping. 


\section{Discussion}

Differentiation of encapsulated hiPSCs to directly produce cardiac tissues in vitro opens a wide range of possibilities in the field of cardiac tissue engineering. Here we show that hiPSCs can be readily and efficiently encapsulated within PEG-fibrinogen hydrogels and directly differentiated to produce uniformly contracting 3D-dhECTs. Gene expression, CM yield, and calcium handling were similar to hiPSC differentiation using the current gold-standard, high efficiency 2D monolayer differentiation. Moreover, using 3D-dhECTs to produce cardiac tissues has distinct advantages over 2D monolayer differentiation ${ }^{39}$ : it enables long-term CM culture and maturation without having to disrupt pre-differentiated SC-CMs, and it does not require the re-formation of functionally critical cell-cell junctions, which is notoriously problematic for CMs, particularly as they mature. The minimal cell-handling requirements and applicability of this cardiac tissue production technique to a wide range of tissue sizes and geometries facilitates high-throughput and cost-effective formation of human cardiac tissue for an array of future applications. PEGfibrinogen can be rapidly photocrosslinked using a non-toxic photoinitiator and visible light, creating a controlled 3D microenvironment for encapsulated cells with potential for automation of the tissue production process using bioprinting of structurally organized microislands and other printed $3 \mathrm{D}$ tissue geometries ${ }^{40,41}$ or microfluidics for microsphere production ${ }^{42,43}$. Previous studies have optimized the initial mechanical properties of the PEG-fibrinogen hydrogels for neonatal CM encapsulation ${ }^{16}$, pre-differentiated SC-CMs encapsulation ${ }^{16,}{ }^{44}$, or SC-CMs seeded onto PEG-fibrinogen hydrogels ${ }^{45}$ (Table S1). However, encapsulation and maintenance of hiPSCs within PEG-fibrinogen, and their direct differentiation in the presence of PEGfibrinogen, had not previously been investigated. The encapsulation procedure established in this study allows for hiPSC survival with maintenance of pluripotency for at least three days within 
this optimized PEG-fibrinogen hydrogel formulation. Maintenance of encapsulated hiPSC pluripotency during extended culture periods has not been investigated; however, other biomaterials have previously been used for large-scale hPSC culture and expansion ${ }^{46-48}$.

Even when varying the initial hiPSC seeding density, cell proliferation and contracting cardiac tissue formation was attainable in PEG-fibrinogen hydrogels (Fig. S7). This robustness is not applicable to the production of contracting $2 \mathrm{D}$ monolayers, where having a tightly defined initial cell-seeding density is critical to success ${ }^{8}$. We believe the biomimetic microenvironment provided by the hydrogel plays a central role in successful hiPSC 3D culture, proliferation, and cardiac differentiation, while initial cell-seeding density may influence the uniformity of contraction within the cardiac tissue over time. Both of these factors directly influence the rate of degradation and temporal remodeling of PEG-fibrinogen hydrogels, allowing cells to secrete ECM proteins and form a continuous tissue. Having a platform that replicates key features of ontogenic cardiac tissue development and CM maturation will enable new opportunities for investigating the process of human heart tissue development.

During initial stages of SC differentiation, we have seen a steady increase in frequency of spontaneous contraction over time (day 8-50), which could be due to the temporal development of cell-cell junctions and calcium handling capabilities of maturing SC-CMs. Based on published results using the small molecule protocol employed in this study ${ }^{8}$, our 3D-dhECTs are likely composed of a distribution of ventricular, atrial, and nodal CM subtypes, which is appropriate for mimicking heart development. To enrich for ventricular myocytes, recently published small molecule differentiation protocols ${ }^{9,49}$ could potentially be adapted for use with our 3D-dhECT system. 3D-dhECT contraction frequency decreased from its maximum of $2.2 \pm 0.1 \mathrm{~Hz}$ on day 50 to $1.35 \pm 0.05 \mathrm{~Hz}$ on day 90 . A reduction in the rate of spontaneous contraction is anticipated 
when modeling the developing human heart; human heart rate in vivo slows down significantly during maturation $(\sim 3.0 \mathrm{~Hz} \text { during fetal stage to } 1.0-1.5 \mathrm{~Hz} \text { in adults })^{50}$.

CM proliferation and hyperplasia is a phenomenon seen during fetal heart growth and early post-natal development ${ }^{51}$, after which it diminishes over time ${ }^{52,53}$. On day 20 of cardiac differentiation, both 2D monolayers and 3D-dhECTs were composed of a similar percentage of CMs. However, the percentage of proliferating CMs in 2D was higher than that in the 3DdhECTs. This difference in CM proliferation was also seen previously between engineered "biowires" and embryoid bodies ${ }^{10}$. Alternatively, considering the low rates of CM proliferation during in vivo development ${ }^{53,54}$ and that cell proliferation rates generally differ in $2 \mathrm{D}$ versus 3D culture $^{55}$, the observed lower CM proliferation might be a consequence of a more physiologic microenvironment in the 3D-dhECTs.

Having a platform that replicates key features of ontogenic CM maturation will enable new opportunities for investigating this critical process, and thereby could provide important insights about how developing human heart tissue remodels after birth. Furthermore, achieving $\mathrm{CM}$ maturation within an in vitro $3 \mathrm{D}$ environment will provide more physiologically relevant tools for toxicology screening and disease modeling using patient-specific hiPSCs ${ }^{56-58}$ to engineer mature cardiac tissues ${ }^{3}$ that current differentiation systems cannot provide. In addition, there is a high demand for cardiac tissues that can be used in patients for myocardial repair ${ }^{59}$; to avoid induction of deadly arrhythmias, clinical applications require CMs that can achieve appropriate mechanical and electrical integration with native tissues. Balancing the needs for both CM plasticity and suitable maturation to achieve this goal is an area of intense research ${ }^{60}$; we have demonstrated that 3D-dhECTs can be used to produce CMs from early time points in 
stem cell differentiation through ultrastructural maturation, providing the flexibility to meet future specifications for optimizing cardiac cell therapy.

T-tubule formation and other mature ultrastructural features that are important in excitation-contraction coupling ${ }^{61,62}$ have been detected in our long-term cultured 3D-dhECT CMs; day 52-60 dissociated CMs showed Caveolin 3 positive staining, indicating the development of T-tubule formation. When incorporated into engineered heart tissue, neonatal rat ventricular myocytes previously have been shown to support formation of T-tubules ${ }^{44}$, however, T-tubule formation in SC-CMs has not been previously reported ${ }^{10,38,39,61,63}$. Initiation of differentiation and long-term culture within an in vitro 3D environment may better support $\mathrm{CM}$ maturation, which is important for establishment of more physiologically relevant tools for toxicology screening and disease modeling of adult human myocardium ${ }^{3}$.

Although immobilized microislands are advantageous for high-throughput applications, this tissue size and geometry also had some drawbacks. At the tested diameter of $6 \mathrm{~mm}$, cell growth and proliferation resulted in non-uniform tissue thickness and the generation of CMs with a range of levels of maturity. Since these regional differences in cell growth were observed prior to the onset of contraction, space limitations at the microisland center could potentially be a contributing factor; in comparison, hiPSCs on tissue edges grew both upwards and radially outwards from the original hydrogel boundaries. In a previous study, a similar tissue morphology (scaffold-free tissue patch) showed higher levels of cardiac maturation and CM purity on tissue edges compared to tissue centers ${ }^{64}$. Additional testing will be required to determine whether observed regional differences in microisland 3D-dhECTs are also observed at smaller diameters or when using alternative fabrication techniques, such as microprinting, versus molds. 
Our study reveals the first 3D ontomimetic model of human heart development, enabling hiPSC growth and cardiac differentiation in a controlled 3D microenvironment. 3D-dhECTs have been used to produce CMs from early time points in SC differentiation through ultrastructural maturation, providing the flexibility to meet future specifications for optimizing cardiac cell therapy. Translatable to a variety of tissue sizes and geometries, this robust approach will ease and improve the cardiac tissue formation process, thereby impacting the ability to produce human heart tissue for a range of applications from investigating the role of 3D microenvironmental cues in human heart development to advancing clinical treatments for heart disease. 


\section{References}

1. Lasser KE, Allen PD, Woolhandler SJ, Himmelstein DU, Wolfe SM and Bor DH. Timing of new black box warnings and withdrawals for prescription medications. Jama. 2002;287:2215-20.

2. Frank C, Himmelstein DU, Woolhandler S, Bor DH, Wolfe SM, Heymann O, Zallman L and Lasser KE. Era of faster FDA drug approval has also seen increased black-box warnings and market withdrawals. Health affairs. 2014;33:1453-9.

3. Yang X, Pabon L and Murry CE. Engineering adolescence: maturation of human pluripotent stem cellderived cardiomyocytes. Circ Res. 2014;114:511-23.

4. Bertassoni LE, Cardoso JC, Manoharan V, Cristino AL, Bhise NS, Araujo WA, Zorlutuna P, Vrana NE, Ghaemmaghami AM, Dokmeci MR and Khademhosseini A. Direct-write bioprinting of cell-laden methacrylated gelatin hydrogels. Biofabrication. 2014;6:024105.

5. Zwi L, Caspi O, Arbel G, Huber I, Gepstein A, Park IH and Gepstein L. Cardiomyocyte differentiation of human induced pluripotent stem cells. Circulation. 2009;120:1513-23.

6. Kattman SJ, Witty AD, Gagliardi M, Dubois NC, Niapour M, Hotta A, Ellis J and Keller G. Stage-specific optimization of activin/nodal and BMP signaling promotes cardiac differentiation of mouse and human pluripotent stem cell lines. Cell stem cell. 2011;8:228-40.

7. Lev S, Kehat I and Gepstein L. Differentiation pathways in human embryonic stem cell-derived cardiomyocytes. Annals of the New York Academy of Sciences. 2005;1047:50-65.

8. Lian X, Zhang J, Azarin SM, Zhu K, Hazeltine LB, Bao X, Hsiao C, Kamp TJ and Palecek SP. Directed cardiomyocyte differentiation from human pluripotent stem cells by modulating Wnt/beta-catenin signaling under fully defined conditions. Nat Protoc. 2013;8:162-75.

9. Burridge PW, Matsa E, Shukla P, Lin ZC, Churko JM, Ebert AD, Lan F, Diecke S, Huber B, Mordwinkin NM, Plews JR, Abilez OJ, Cui B, Gold JD and Wu JC. Chemically defined generation of human cardiomyocytes. Nat Methods. 2014;11:855-60.

10. Nunes SS, Miklas JW, Liu J, Aschar-Sobbi R, Xiao Y, Zhang B, Jiang J, Masse S, Gagliardi M, Hsieh A, Thavandiran N, Laflamme MA, Nanthakumar K, Gross GJ, Backx PH, Keller G and Radisic M. Biowire: a platform for maturation of human pluripotent stem cell-derived cardiomyocytes. Nat Methods. 2013;10:781-7.

11. Turnbull IC, Karakikes I, Serrao GW, Backeris P, Lee JJ, Xie C, Senyei G, Gordon RE, Li RA, Akar FG, Hajjar RJ, Hulot JS and Costa KD. Advancing functional engineered cardiac tissues toward a preclinical model of human myocardium. FASEB J. 2014;28:644-54.

12. Zhang D, Shadrin IY, Lam J, Xian HQ, Snodgrass HR and Bursac N. Tissue-engineered cardiac patch for advanced functional maturation of human ESC-derived cardiomyocytes. Biomaterials. 2013;34:5813-20.

13. Schaaf S, Shibamiya A, Mewe M, Eder A, Stohr A, Hirt MN, Rau T, Zimmermann WH, Conradi L, Eschenhagen $\mathrm{T}$ and Hansen A. Human engineered heart tissue as a versatile tool in basic research and preclinical toxicology. PLoS One. 2011;6:e26397.

14. Tulloch NL, Muskheli V, Razumova MV, Korte FS, Regnier M, Hauch KD, Pabon L, Reinecke H and Murry CE. Growth of engineered human myocardium with mechanical loading and vascular coculture. Circulation research. 2011;109:47-59.

15. Mihic A, Li J, Miyagi Y, Gagliardi M, Li SH, Zu J, Weisel RD, Keller G and Li RK. The effect of cyclic stretch on maturation and 3D tissue formation of human embryonic stem cell-derived cardiomyocytes. Biomaterials. 2014;35:2798-808.

16. Shapira-Schweitzer K and Seliktar D. Matrix stiffness affects spontaneous contraction of cardiomyocytes cultured within a PEGylated fibrinogen biomaterial. Acta biomaterialia. 2007;3:33-41.

17. Mironi-Harpaz I, Wang DY, Venkatraman S and Seliktar D. Photopolymerization of cell-encapsulating hydrogels: crosslinking efficiency versus cytotoxicity. Acta Biomater. 2012;8:1838-48.

18. Dikovsky D, Bianco-Peled $\mathrm{H}$ and Seliktar D. The effect of structural alterations of PEG-fibrinogen hydrogel scaffolds on 3-D cellular morphology and cellular migration. Biomaterials. 2006;27:1496-506.

19. Franco CL, Price J and West JL. Development and optimization of a dual-photoinitiator, emulsion-based technique for rapid generation of cell-laden hydrogel microspheres. Acta Biomater. 2011;7:3267-76.

20. Lian X, Hsiao C, Wilson G, Zhu K, Hazeltine LB, Azarin SM, Raval KK, Zhang J, Kamp TJ and Palecek SP. Robust cardiomyocyte differentiation from human pluripotent stem cells via temporal modulation of canonical Wnt signaling. Proc Natl Acad Sci U S A. 2012;109:E1848-57. 
21. Beers J, Gulbranson DR, George N, Siniscalchi LI, Jones J, Thomson JA and Chen G. Passaging and colony expansion of human pluripotent stem cells by enzyme-free dissociation in chemically defined culture conditions. Nature protocols. 2012;7:2029-40.

22. Nie Y, Walsh P, Clarke DL, Rowley JA and Fellner T. Scalable passaging of adherent human pluripotent stem cells. PloS one. 2014;9:e88012.

23. Lowes BD, Minobe W, Abraham WT, Rizeq MN, Bohlmeyer TJ, Quaife RA, Roden RL, Dutcher DL, Robertson AD, Voelkel NF, Badesch DB, Groves BM, Gilbert EM and Bristow MR. Changes in gene expression in the intact human heart. Downregulation of alpha-myosin heavy chain in hypertrophied, failing ventricular myocardium. The Journal of clinical investigation. 1997;100:2315-24.

24. Itzhaki I, Rapoport S, Huber I, Mizrahi I, Zwi-Dantsis L, Arbel G, Schiller J and Gepstein L. Calcium handling in human induced pluripotent stem cell derived cardiomyocytes. PloS one. 2011;6:e18037.

25. Lou Q, Fedorov VV, Glukhov AV, Moazami N, Fast VG and Efimov IR. Transmural heterogeneity and remodeling of ventricular excitation-contraction coupling in human heart failure. Circulation. 2011;123:1881-90.

26. Planat-Benard V, Menard C, Andre M, Puceat M, Perez A, Garcia-Verdugo JM, Penicaud L and Casteilla L. Spontaneous cardiomyocyte differentiation from adipose tissue stroma cells. Circ Res. 2004;94:223-9.

27. Matsuura K, Nagai T, Nishigaki N, Oyama T, Nishi J, Wada H, Sano M, Toko H, Akazawa H, Sato T, Nakaya H, Kasanuki $\mathrm{H}$ and Komuro I. Adult cardiac Sca-1-positive cells differentiate into beating cardiomyocytes. J Biol Chem. 2004;279:11384-91.

28. Zimmermann WH, Schneiderbanger K, Schubert P, Didie M, Munzel F, Heubach JF, Kostin S, Neuhuber WL and Eschenhagen T. Tissue engineering of a differentiated cardiac muscle construct. Circulation research. 2002;90:223-30.

29. Fink C, Ergun S, Kralisch D, Remmers U, Weil J and Eschenhagen T. Chronic stretch of engineered heart tissue induces hypertrophy and functional improvement. FASEB journal : official publication of the Federation of American Societies for Experimental Biology. 2000;14:669-79.

30. Tiburcy M, Didie M, Boy O, Christalla P, Doker S, Naito H, Karikkineth BC, El-Armouche A, Grimm M, Nose M, Eschenhagen T, Zieseniss A, Katschinksi DM, Hamdani N, Linke WA, Yin X, Mayr M and Zimmermann WH. Terminal differentiation, advanced organotypic maturation, and modeling of hypertrophic growth in engineered heart tissue. Circulation research. 2011;109:1105-14.

31. Radisic M, Park H, Shing H, Consi T, Schoen FJ, Langer R, Freed LE and Vunjak-Novakovic G. Functional assembly of engineered myocardium by electrical stimulation of cardiac myocytes cultured on scaffolds. Proceedings of the National Academy of Sciences of the United States of America. 2004;101:18129-34.

32. Hirt MN, Boeddinghaus J, Mitchell A, Schaaf S, Bornchen C, Muller C, Schulz H, Hubner N, Stenzig J, Stoehr A, Neuber C, Eder A, Luther PK, Hansen A and Eschenhagen T. Functional improvement and maturation of rat and human engineered heart tissue by chronic electrical stimulation. J Mol Cell Cardiol. 2014;74:151-61.

33. Bird SD, Doevendans PA, van Rooijen MA, Brutel de la Riviere A, Hassink RJ, Passier R and Mummery CL. The human adult cardiomyocyte phenotype. Cardiovascular research. 2003;58:423-34.

34. Gerdes AM, Kellerman SE, Moore JA, Muffly KE, Clark LC, Reaves PY, Malec KB, McKeown PP and Schocken DD. Structural remodeling of cardiac myocytes in patients with ischemic cardiomyopathy. Circulation. 1992;86:426-30.

35. Ziman AP, Ward CW, Rodney GG, Lederer WJ and Bloch RJ. Quantitative measurement of $\mathrm{Ca}(2)(+)$ in the sarcoplasmic reticulum lumen of mammalian skeletal muscle. Biophysical journal. 2010;99:2705-14.

36. Knollmann BC. Induced pluripotent stem cell-derived cardiomyocytes: boutique science or valuable arrhythmia model? Circ Res. 2013;112:969-76; discussion 976.

37. Robertson C, Tran DD and George SC. Concise review: maturation phases of human pluripotent stem cellderived cardiomyocytes. Stem Cells. 2013;31:829-37.

38. Priori SG, Napolitano C, Di Pasquale E and Condorelli G. Induced pluripotent stem cell-derived cardiomyocytes in studies of inherited arrhythmias. J Clin Invest. 2013;123:84-91.

39. Lundy SD, Zhu WZ, Regnier $M$ and Laflamme MA. Structural and functional maturation of cardiomyocytes derived from human pluripotent stem cells. Stem cells and development. 2013;22:19912002.

40. Murphy SV and Atala A. 3D bioprinting of tissues and organs. Nat Biotechnol. 2014;32:773-85.

41. Stanton MM, Samitier J and Sanchez S. Bioprinting of 3D hydrogels. Lab Chip. 2015;15:3111-5. 
42. Workman VL, Dunnett SB, Kille P and Palmer DD. Microfluidic chip-based synthesis of alginate microspheres for encapsulation of immortalized human cells. Biomicrofluidics. 2007;1:14105.

43. Chung BG, Lee KH, Khademhosseini A and Lee SH. Microfluidic fabrication of microengineered hydrogels and their application in tissue engineering. Lab Chip. 2012;12:45-59.

44. Shapira-Schweitzer K, Habib M, Gepstein L and Seliktar D. A photopolymerizable hydrogel for 3-D culture of human embryonic stem cell-derived cardiomyocytes and rat neonatal cardiac cells. Journal of molecular and cellular cardiology. 2009;46:213-24.

45. Bearzi C, Gargioli C, Baci D, Fortunato O, Shapira-Schweitzer K, Kossover O, Latronico MV, Seliktar D, Condorelli G and Rizzi R. PIGF-MMP9-engineered iPS cells supported on a PEG-fibrinogen hydrogel scaffold possess an enhanced capacity to repair damaged myocardium. Cell Death Dis. 2014;5:e1053.

46. Lei Y and Schaffer DV. A fully defined and scalable 3D culture system for human pluripotent stem cell expansion and differentiation. Proceedings of the National Academy of Sciences of the United States of America. 2013;110:E5039-48.

47. Amit M, Laevsky I, Miropolsky Y, Shariki K, Peri M and Itskovitz-Eldor J. Dynamic suspension culture for scalable expansion of undifferentiated human pluripotent stem cells. Nature protocols. 2011;6:572-9.

48. Zweigerdt R, Olmer R, Singh H, Haverich A and Martin U. Scalable expansion of human pluripotent stem cells in suspension culture. Nature protocols. 2011;6:689-700.

49. Weng Z, Kong CW, Ren L, Karakikes I, Geng L, He J, Chow MZ, Mok CF, Keung W, Chow H, Leung AY, Hajjar RJ, Li RA and Chan CW. A simple, cost-effective but highly efficient system for deriving ventricular cardiomyocytes from human pluripotent stem cells. Stem Cells Dev. 2014;23:1704-16.

50. Arduini D. Fetal Cardiac Function. 1995:43-49.

51. Li F, Wang X, Capasso JM and Gerdes AM. Rapid transition of cardiac myocytes from hyperplasia to hypertrophy during postnatal development. Journal of molecular and cellular cardiology. 1996;28:173746.

52. Laflamme MA and Murry CE. Heart regeneration. Nature. 2011;473:326-35.

53. Mollova M, Bersell K, Walsh S, Savla J, Das LT, Park SY, Silberstein LE, Dos Remedios CG, Graham D, Colan S and Kuhn B. Cardiomyocyte proliferation contributes to heart growth in young humans. Proceedings of the National Academy of Sciences of the United States of America. 2013;110:1446-51.

54. Bensley JG, Stacy VK, De Matteo R, Harding R and Black MJ. Cardiac remodelling as a result of pre-term birth: implications for future cardiovascular disease. European heart journal. 2010;31:2058-66.

55. Mann BK and West JL. Cell adhesion peptides alter smooth muscle cell adhesion, proliferation, migration, and matrix protein synthesis on modified surfaces and in polymer scaffolds. Journal of biomedical materials research. 2002;60:86-93.

56. Liang P, Lan F, Lee AS, Gong T, Sanchez-Freire V, Wang Y, Diecke S, Sallam K, Knowles JW, Wang PJ, Nguyen PK, Bers DM, Robbins RC and Wu JC. Drug screening using a library of human induced pluripotent stem cell-derived cardiomyocytes reveals disease-specific patterns of cardiotoxicity. Circulation. 2013;127:1677-91.

57. Doyle MJ, Lohr JL, Chapman CS, Koyano-Nakagawa N, Garry MG and Garry DJ. Human Induced Pluripotent Stem Cell-Derived Cardiomyocytes as a Model for Heart Development and Congenital Heart Disease. Stem Cell Rev. 2015;11:710-27.

58. Yazawa M, Hsueh B, Jia X, Pasca AM, Bernstein JA, Hallmayer J and Dolmetsch RE. Using induced pluripotent stem cells to investigate cardiac phenotypes in Timothy syndrome. Nature. 2011;471:230-4.

59. Chong JJ, Yang X, Don CW, Minami E, Liu YW, Weyers JJ, Mahoney WM, Van Biber B, Cook SM, Palpant NJ, Gantz JA, Fugate JA, Muskheli V, Gough GM, Vogel KW, Astley CA, Hotchkiss CE, Baldessari A, Pabon L, Reinecke H, Gill EA, Nelson V, Kiem HP, Laflamme MA and Murry CE. Human embryonic-stem-cell-derived cardiomyocytes regenerate non-human primate hearts. Nature. 2014;510:2737.

60. Dunn DA, Hodge AJ and Lipke EA. Biomimetic materials design for cardiac tissue regeneration. Wiley interdisciplinary reviews Nanomedicine and nanobiotechnology. 2014;6:15-39.

61. Lieu DK, Liu J, Siu CW, McNerney GP, Tse HF, Abu-Khalil A, Huser T and Li RA. Absence of transverse tubules contributes to non-uniform $\mathrm{Ca}(2+)$ wavefronts in mouse and human embryonic stem cell-derived cardiomyocytes. Stem Cells Dev. 2009;18:1493-500.

62. Wei S, Guo A, Chen B, Kutschke W, Xie YP, Zimmerman K, Weiss RM, Anderson ME, Cheng H and Song LS. T-tubule remodeling during transition from hypertrophy to heart failure. Circulation research. 2010;107:520-31. 
63. Baharvand H, Azarnia M, Parivar K and Ashtiani SK. The effect of extracellular matrix on embryonic stem cell-derived cardiomyocytes. Journal of molecular and cellular cardiology. 2005;38:495-503.

64. Stevens KR, Pabon L, Muskheli V and Murry CE. Scaffold-free human cardiac tissue patch created from embryonic stem cells. Tissue engineering Part A. 2009;15:1211-22.

\section{Acknowledgments}

This work was funded by the National Science Foundation (NSF) CBET-1150854 (E.A.L.), and CBET-1403495 (C.J.E.), as well as the US National Institutes of Health (NIH)/NHLBI through grant 2T32HL007824-16A1 (I.C.T.) and NIH/NHLBI Program of Excellence in Nanotechnology (PEN) Award, Contract HHSN268201000045C (K.D.C.), and grant R01DK093810 (C.J.E.). P.K. held an American Heart Association pre-doctoral fellowship AHA -13PRE1470078 and A.J.H. an AL-EPSCoR GRSP fellowship. We would like to thank Dr. Ronald Gordon, Department of Pathology at Mount Sinai, for performing transmission electron microscopy; Dr. Juming Zhong, Auburn University, for technical support in calcium transient imaging; Dr. Elizabeth Schwartz and Allison Church Bird, Auburn University, for technical expertise and support in flow cytometry; Dr. Vishnu Suppiramaniam for providing assistance with multielectrode array (MEA) experiments. Scientific illustrations were graciously created by Brennen Reece. 